\title{
Quando o passado atropela o presente: notas de um Brasil que insiste no racismo
}

\author{
L LILIA SCHWARCZ \\ Universidade de São Paulo, São Paulo, São Paulo, Brasil \\ Hélio Menezes Neto \\ Universidade de São Paulo, São Paulo, São Paulo, Brasil
}

Dol 10.11606/issn.2316-9133.v25i25p31-35

"Sanccionado o projecto que extingue a escravidão no Brazil, encerrou-se o periodo negro da nossa Historia." Foi dessa maneira que o jornal O Paiz noticiou a Lei Imperial no 3.353 que decretava, em 13 de maio de 1888, o fim do cativeiro no país. A ambiguidade da frase, que teimava em usar "negro" como adjetivo infausto e relegá-lo a um dado inerte do passado, ausente dos projetos de futuro da nação, não deixa de ser curiosa, ao mesmo tempo que perversa. Entre o dito e os muitos não ditos que a compõem, o texto curto da nota acaba por trazer à tona várias das contradições que o momento ensejava e que ainda enseja nos dias de hoje. A maioria delas absolutamente atual.

A festejada lei, que veio a ser batizada de Áurea, logo revelou seu brilho de intensidade limitada. Se, de um lado, liberdade era moeda difícil de lograr, de outro era ainda mais complicada para manter. Desacompanhada de qualquer política de promoção efetiva de cidadania e de inclusão social dos agora ex-escravizados, o resultado da medida relegou uma enorme população de africanos e seus descendentes à própria sorte. A vigência por tantos séculos de um sistema assentado na violência e no arbítrio da propriedade de um indivíduo por outro acabou por legitimar e postergar no país uma rígida hierarquia. Combinada com as novas vogas do determinismo racial de finais do XIX - que naturalizava a diferença -, enraizou uma série de discriminações que em nada devem à natureza; são fruto da própria sociedade. Num país marcado pela desigualdade de oportunidades e por grande assimetria de acesso a direitos, a escravidão, embora formalmente extinta, encontrou terreno fértil para fazer perdurar seus efeitos. Além do mais, virou linguagem social, tornando vigente uma espécie de vocabulário de cores que passa a impressão de produzir uma sociedade mais fluida, mas que, na verdade, produz novas discriminações que atuam tal qual dialeto nativo.

O racismo existente na sociedade brasileira é, assim, uma das graves consequências desse modelo que se fincou entre nós. Se as teorias científicas sobre raça, que determinavam existir entre os grupos humanos diferenças essenciais, 
foram desacreditadas pelas modernas pesquisas em ciências sociais e biologia genética, o racismo que as embasa continuou a reinventar-se em novas práticas e retóricas políticas, sociais e culturais. Longe de ser um tema relegado ao passado, como parte do discurso oficial e do senso comum faz crer, a correlação entre características fenotípicas (como cor de pele ou tipo de cabelo) e atributos subjetivos (como inteligência, capacidades morais ou disposições físicas) ainda é moeda corrente na economia das nossas relações sociais.

Tal correlação pode envolver, ainda, fatores para além da raça - ou, melhor dizendo, fatores que a atravessam e por vezes a constituem, sugerindo-lhe novos conteúdos. O racismo em suas manifestações mais concretas não raro se expressa articulado a outros marcadores sociais da diferença, como gênero, classe, região, sexualidade e geração, num jogo de mútua determinação e causalidade.

Nada como trazer um exemplo recente. Os massacres ocorridos em presídios de Roraima, Amazonas e Rio Grande do Norte, logo nos primeiros dias deste ano de 2017, vêm confirmar tal imbricação num cenário desolador: a morte de mais de 130 pessoas numa região distante do centro do país. Nas fotografias das chacinas, destaca-se uma composição similar a outro inglório episódio de violência prisional que marcou nossa história. Os encarcerados do Norte e Nordeste, como os do Carandiru, em sua maioria jovens de origem periférica, são "quase todos pretos, ou quase pretos, ou quase brancos quase pretos de tão pobres", como bem descrevem os versos da canção de Caetano e Gil. As semelhanças aqui não são mera coincidência. Segundo dados do Sistema Integrado de Informação Penitenciária (Infopen), em 2014, 67\% da população carcerária do Brasil era negra; 56\% entre 18 e 29 anos. É público, e ao mesmo tempo acobertado, como estamos praticando o genocídio de uma geração de negros, e em todas as regiões do país.

As reações do poder público diante desses episódios foram sintomáticas, a designar como "acidente" o que funcionários das penitenciárias chamaram de "barbárie" e "matança". Isso sem esquecer dos comentários mais extremos, a desejar que cenas como essas se repetissem em outros lugares. Para além de seus emissores mais imediatos e recorrentes - ministros e autoridades supostamente competentes -, tais discursos faziam também ecoar parte significativa da opinião pública. Expunham ainda uma certa conivência de parte da sociedade com a evidente seletividade punitiva em curso no país.

Os dados são conclusivos e não nos deixam desviar do assunto: a cada 23 minutos, um jovem negro é assassinado no Brasil. Segundo estudo divulgado no Mapa da Violência (2016), cerca de 30 mil jovens entre 15 e 29 anos são vítimas de homicídio anualmente no país; 77\% deles, negros. A taxa é quase quatro vezes superior à registrada entre brancos de mesma idade. O número já seria escandaloso se não escondesse a notória subnotificação de mortes causadas pela polícia, a qual, propositalmente, procura empurrar esses já elevados números para baixo. 
Os tristes eventos que abriram o ano de 2017 não configuram, porém, casos isolados, seguindo o rasto de sucessivas ocorrências em 2016. Este, um longo ano que parece resistir a acabar no que se refere ao tema que se convencionou chamar de "questão racial", deixou cicatrizes profundas e nada acidentais. Uma das mais marcantes foi a ocorrida em 17 de abril, tendo a Câmara dos Deputados como teatro de cenas explícitas de "familismo". Nesse dia, o país assistiu, entre estupefato e envergonhado, a um perfil monótono de congressistas, que supostamente o representa, suceder-se à tribuna para votar pelo impeachment da presidente. Motivados pelos interesses mais domésticos, falando em nome de suas próprias famílias e de Deus, homens em sua maioria brancos e de meia idade, de classes abastadas e publicamente heterossexuais alternavam-se entre demonstrações de homofobia, misoginia, com direito até a apologia à tortura; tudo transmitido ao vivo pela TV. Eram raras, muito raras, as vozes destoantes. A diversidade da população brasileira ali se fez ausente. Junto com ela, eram igualmente golpeados os valores democráticos e nossa combalida tradição republicana.

A composição ministerial do novo governo que se instalou na sequência seguiu a mesma receita monotonamente repetida. Entre os 23 novos ministros empossados, nenhum negro. Foi também, ao menos desde o mandato de Ernesto Geisel, a primeira formação sem nenhuma mulher no alto escalão do poder. E os efeitos de tal uniformidade não se restringiram aos dirigentes, logo se espraiando na própria divisão institucional da República. A Medida Provisória 726/2016, primeiro ato adotado por Michel Temer no exercício interino da presidência, já indiciava o que seria uma constante da nova gestão: o confisco de direitos e espaços de formação política que pareciam, enganosamente, até então assegurados. Entre as primeiras mudanças, a extinção do Ministério da Cultura, do Ministério das Mulheres, da Igualdade Racial, da Juventude e dos Direitos Humanos, bem como da Controladoria Geral da União, entre outras pastas e importantes espaços de prática e vigilância cidadãs. Movimentos negros, feministas, LGBT, quilombolas, de artistas e operadores da cultura se inteiravam, na manhã do 13 de maio de 2016, da perda de seu lugar autônomo de representação e formulação de políticas públicas. A coincidência da data para tamanha perda de perspectivas de futuro não poderia ser mais perniciosa.

Estatísticas atualizadas também têm ajudado a embasar o pessimismo das previsões que fez parte da inauguração deste ano de 2017. A taxa de analfabetismo entre negros $(27,4 \%)$, por exemplo, é quase cinco vezes maior do que entre brancos $(5,9 \%)$, considerando-se todas as faixas etárias (segundo o Censo de 2010). No tocante à saúde, para tomarmos apenas um dos muitos índices de um racismo inequivocamente institucional, a razão de mortalidade materna entre mulheres negras é 66\% maior do que entre brancas, segundo dados do Sistema de Informação sobre Mortalidade (SIM) do Ministério da Saúde. Os dados do IBGE/PNAD (2014) mostram que aqui pobreza tem mesmo cor definida: entre os $10 \%$ mais pobres, $76 \%$ são negros; já entre os $1 \%$ mais ricos, esse número cai 
para $15 \%$. Isso num país em que os negros compõem mais da metade da população $(53,6 \%)$.

A pretensa imparcialidade dos números não deixa escapar, portanto, a existência de um racismo encarnado em nosso cotidiano. São crianças negras que desde pequenas têm seus cabelos e outros traços fisionômicos diminuídos, especialmente na escola; que crescem com pouca ou nenhuma referência de representatividade positiva na TV ou nas prateleiras das lojas de brinquedo; que aprendem desde cedo a sonhar com príncipes loiros e alvas princesas de filmes infantis. Ao longo de suas vidas, serão confrontadas com muitos obstáculos difíceis de transpor: dos postos mais altos no mercado de trabalho, das universidades de ponta, de clubes e casas de lazer, dos restaurantes elegantes (onde nem o garçom pode ser negro), das batidas policiais, do táxi que, mesmo vazio, recusa-se a parar.

Os exemplos são muitos, e carregam, cada um deles, sua própria dose de violência, humilhação e injustiça. Embora tais ações possam implicar a incidência de responsabilidade penal, o artigo 140 do Código Penal, que prevê o crime de injúria racial (relativo à pessoa), bem como a Lei 7.716/1989, que define o crime de racismo (relativo a uma coletividade), são na prática pouco acionados. As dificuldades regimentais de comprovação do crime e o reiterado hábito de minimizar atos de racismo, como se não passassem de brincadeiras de mau gosto ou mal-entendidos circunstanciais, concorrem para a pouca efetividade dos mecanismos legais de penalidade e reparação. A lei aqui, como a expressão popular confirma, é mesmo para poucos.

Último país do Ocidente a abolir a escravidão e campeão nos índices atuais de desigualdade, o Brasil ainda carrega uma enorme dívida para com seus afrodescendentes. E não há como desempatar a partida sem manter os olhos bem abertos para o passado, mas dirigi-los igualmente para o presente. A marcha que vem sendo desenvolvida no país lembra de perto o passo de caranguejo; aquele que parece avançar dois para frente e recua com três para trás. Depois da promulgação da Constituição Cidadã, em 1988, a qual seria motivo de orgulho para qualquer nação, temos insistido em sistematicamente abrir mão das nossas conquistas e do nosso direito inalienável à pluralidade; índice de uma democracia saudável.

Um projeto de país mais equitativo haverá de passar necessariamente pelo reconhecimento de nossos desacertos de hoje, bem como pelo enfrentamento de nossas pesadas heranças históricas. Só assim se poderá supor e imaginar qualquer utopia boa de superação. Ou, como bem ensinam os versos de Mário Quintana, "nós vivemos a temer o futuro/ mas é o passado [e o presente] que nos atropela e mata". 


\section{autores Lilia Moritz Schwarcz}

Professora da Universidade de São Paulo (USP) e Global Scholar em Princeton, é autora, entre outros, de O espetáculo das raças, As barbas do imperador, O sol do Brasil e Brasil: uma biografia. Foi curadora de uma série de exposições dentre as quais: "Um olhar sobre o Brasil" e "Histórias Mestiças". Atualmente é curadora adjunta do Masp.

\section{Hélio Menezes Neto}

Graduado em Relações Internacionais e Ciências Sociais pela Universidade de São Paulo (USP). Mestrando pelo Programa de Pós-Graduação em Antropologia Social da mesma universidade, atua também como pesquisador do Núcleo de Marcadores Sociais da Diferença (NUMAS) e do Núcleo Etno-história.

Recebido em 20/01/2017 Aceito para publicação em 20/01/2017 